\title{
Factors Driving Subscribers Mobile Network Service and Provider Choice: An Exploratory Study from Ghana
}

\author{
Mavis Agyapomah Baafi ${ }^{*} \quad$ Jiang Xin-Ying \\ School of Management, Jiangsu University, Zhenjiang, 212013, China
}

\begin{abstract}
This study examines the key factors influencing mobile network service and provider choice among 415 subscribers in Ghana. To meet the objectives of this research, an administered questionnaire of a descriptive manner was developed based on thorough review of literature and elicitation interviews. Exploratory data analysis was performed using statistical softwares and the results of the analysis was established on the aims of this research. Factors such as family and friends, network signal strength, low voice and internet rate, moderate cost of services, nationwide coverage, clear and uncongested network, consistent and dependable mobile network were essential to respondents choice in selecting one service provider over other alternatives. Interestingly, the company's brand/participation in charity was among the least considered factors. Respondents chose fast data connectivity and rollover of data bundles as the most crucial factor to consider when switching to a new mobile network provider. Authors recommend that the mobile network providers should invest significantly in technological innovations that provide clear and uncongested network, enhanced coverage, faster data services and have lower call and data charges. Understanding the factors affecting subscribers to choose one service provider over the other can be very beneficial for mobile network service providers to learn more about their subscribers to attain and retain them and potentially contribute to the firm's financial success.
\end{abstract}

Keywords: mobile network service, mobile network service provider, subscriber's choice, Ghana

DOI: $10.7176 / \mathrm{JMCR} / 66-04$

Publication date:March $31^{\text {st }} 2020$

\section{Introduction}

Globally, there has been rapid advancement in technology, along with a surge in mobile devices penetration in recent years. At the end of 2020, mobile phone subscriptions across the globe was forecasted to reach 5.7 billion, according to Statista (Note 1). The mobile communication system is an integral part of today's life, which has caused mobile service providers to increase all over the world.

Most countries have opened up the telecommunication industry by allowing more players to get involved in the mobile phone service sector. The emergence of mobile telephony in Africa has been essential in promoting telecommunication services, which has helped in the increase in the number of telecommunication users. Factors such as demand, sector reforms, licensing and emergence of investors have enabled mobile phone usage to rise. According to Statista (Note 2), mobile subscriber numbers in Ghana have increased rapidly from 1.7 million in 2004 to 36.75 million in 2017 to 40.93 million in 2018.

The introduction of new methods of communication and developments in information technology has resulted in significant changes in consumer behaviour. These advancements have created a shift in companies' focus, especially in the telecommunication industry, although it is rewarding in many aspects. The industry has witnessed a wave of critical structural changes in its competition, strategies, techniques, and even technological environment. To achieve its goals, the industry must deliver an unforgettable experience to the subscribers to retain, reassure and confirm the monetary worth on purchases.

The decision to purchase a product or service by consumers involves several factors that influences their choice. The new subscriber or those who wish to switch is the focus of the mobile network service providers, and thus they are lured with all kinds of attractive packages. Since first impressions or getting it right the first time is essential (Lockwood, 1994; McDougall and Levesque, 2000), anticipating or aiding the decision making process of subscribers, especially those that consider various service providers could prove very valuable to service marketers. Subscribers might choose a network base on its service quality and price (Melody, 2001), contract features (Alshurideh, 2016) geographical areas, and multiple products (Chan-Olmsted and Jamison, 2001), loyalty program, quality ratings.

The phase of consumer decision-making as it pertains to mobile network choice has been over the years deliberated considerably in academia and industry; not least concerning the broad array of possible influencing factors thought to explain actual mobile network service choice. The practitioner and research circles have had an interest in ascertaining influencing factors believed to drive subscribers' decision as to which mobile network provider to subscribe. Various researches have been performed to evaluate such influencing factors including but not limited to service fairness, service quality, price fairness perception (Choi, 2008; Hassan et al., 2013; Gautam, 2015), mobile service bundles, price (Klein and Jakopin, 2014), cooperate image, consumer expectation, and perceived value (Ali et al., 2015; Segerra-Monilah and Moliner -Tena, 2016; Chuah et al., 2016). In a study by 
Alan et al. (2016), results show mobile telecommunication industries must focus on reducing the gap between consumer perceptions and expectations in connection to the service quality if mobile network providers are to be operational and increase by pricing strategy, network facilities, and promotional activities.

According to Nimako (2012), in a study to find out the extent to which service quality affects subscribers' satisfaction and behavior intention, it was discovered customer relations, network quality, and tangibles positively affects customer satisfaction, which, in turn impacts behavior intention in the Ghana Mobile Telecommunication Industry (GMTI). The results from Agyapong (2011) showed all service quality items: reliability, tangibility, assurance, responsiveness, and empathy were good predictors of customer satisfaction. There exist a positive relationship between price, service quality, brand image, value offered, and customer loyalty (Koi-Akrofi et al., 2013). Bansah et al. (2015) disclosed that branding complemented by other factors such as status, price, lifestyle, and self-concept are crucial constituents in affecting a customer's purchase decision. In turn, the above research works have shown that the factors studied are key to influencing the subscribers' choice set and final decision of network subscription.

Other studies have focused on the facet of perceived service quality in the mobile network service sector. According to Ayden and Ozer, 2005, perceived service quality is necessitous but not an adequate condition for purchase intention and consumer loyalty. Numerous factors impact consumer buying decision processes; they include individual elements such as personality, values, attitudes, motivation, perception, lifestyle, and learning affect the process. Personal influence, family influence, reference group, social class or cultures are social factors that affect consumers buying decisions and affect behavioral intentions.

Despite the research mentioned above related to service quality as a relevant element in the mobile subscriber choice and satisfaction, other factors categorized in this study as demography, technical, efficiency, economic, and social-related factors have not been thoroughly addressed in the GMTI as a driving tool for subscribers' choice. The study was carried out in Ghana and was part of a broader research work investigating mobile network experience that drives positive electronic word-of-mouth. Given the recent price hike in mobile data services culminating into the "\#SaveOurData" campaign because of the increment of communication service tax by the Ghana government, it was deemed insightful to investigate factors affecting subscribers' choice of mobile network service provider.

In recent times where consumers have different choices, the pattern of consumption is changing, and consumers and other forms of demand are increasing. Studying and knowing these developments is crucial for awareness and knowledge for the Ghana mobile network service providers. Based on thorough literature review and respondents' direct feedback, this research work propositioned a conceptual framework, as shown in Figure 1 to capture the most significant factors influencing subscribers' choice of a mobile network service provider. From the framework illustration, this study aims to contribute to the literature by not only corroborating and or disagreeing to the results from other research but to ascertain possible latest developments. To this end, the issues presented above are the motives behind this research work. Specifically, this study wants to provide answers to these research questions:

- Which one factor more than any other does drive subscribers' decision to subscribe to one mobile service provider over another?

- Which factors are most or least important in influencing subscribers' choice of a mobile network service provider? Does the order of preference of the factors among subscribers vary by demographic factors?

- Which mobile network services do subscribers mostly use?

- Does the order of preference for the usage of various mobile network services among subscribers differ by age?

- If subscribers were to switch from their current mobile network service providers, what features should the new service provider have?

Knowing and understanding the factors affecting subscribers to choose one service provider over the other can be very beneficial to the mobile service providers to learn more about their subscribers in order to attain and retain them and potentially contribute to the firm's financial success. 


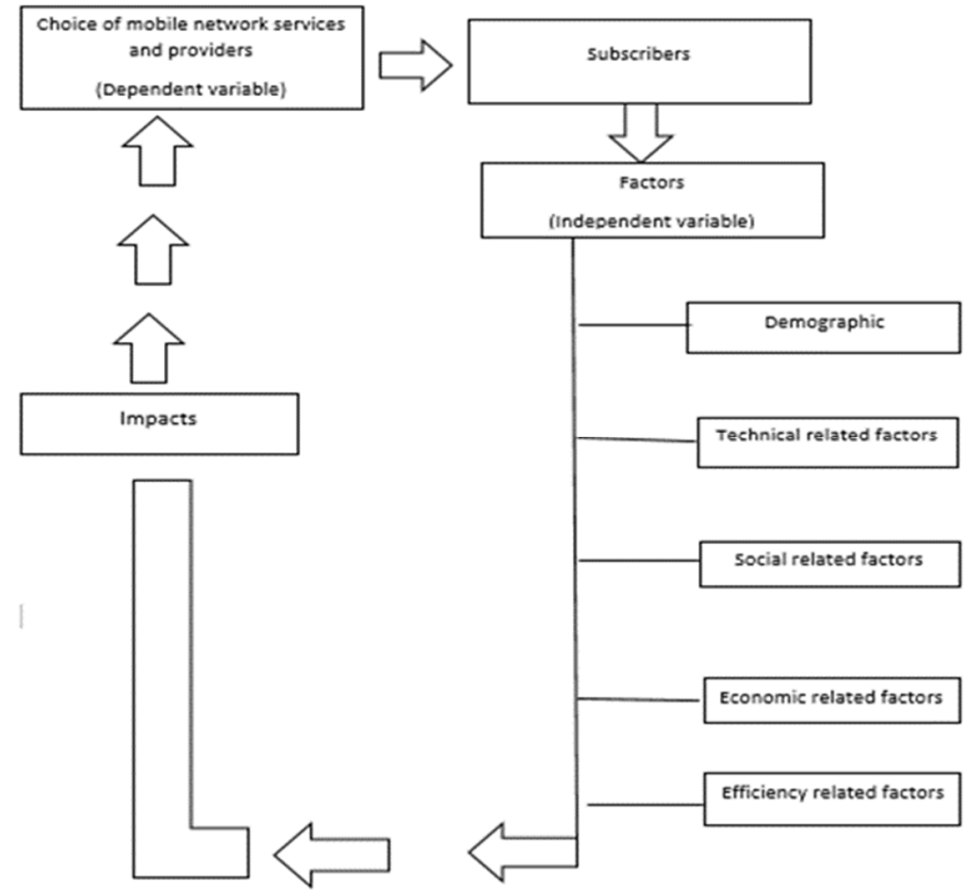

Figure 1. Framework illustrating aspect concerned with subscribers' choice of mobile network service and provider

This paper is organized as follows. Section 2 presents the research methodology. Results from data analysis and discussion are presented in section 3 . The last section presents concluding remarks, implications, limitations and future research path.

\section{Research Methodology}

\subsection{Development of Questionnaire}

To meet the objectives of this research, an administered questionnaire of a descriptive manner was developed based on thorough review of literature and elicitation interviews. Subsequently, a pilot study was performed to examine the questionnaire's content validity. Thirty subscribers provided suggestions and comments. The questionnaire was improved using the feedback received from the respondents. To prevent possible misinterpretation, authors added a concise clarification of the concept of consumer choice and information on Ghana's mobile service providers.

The questionnaire consist of various sections covering the following matters: the first section studied respondents' use of mobile service network as well as socio-demographic information, which included gender, age, marital status, occupation, among others. The second part asked respondents in their own words factors that influence subscriber choice. The third section focused on the importance of mobile network attributes or items (Table 7). The fourth section addresses groups (age, gender) and the use of mobile network service. Lastly, Section 5 asked respondents to select attributes they want their new mobile network provider to have. A 5-point Likert scale was used in measuring the importance of these factors.

\subsection{Data collection and sampling procedure}

The target population consists of single users of mobile network services in Ghana. As per 2017 information from Statista, in the over 25 years since mobile was established in Ghana, the industry has connected about 36.75 million subscribers. The sample size of this research work was computed using the approach proposed by Cochran (1977):

$$
\mathrm{n}_{0}=(((Z \text {-value })) 2 \times \sigma \times(1-\sigma)) / \mathrm{e} 2,
$$

where $\mathrm{n}_{0}$ is the sample size, $Z$ - value describes the confidence level $(95 \%), \sigma$ is the level of variability $(0.5)$ and $\mathrm{e}$ is the desired level of precision ( + or $-5 \%$ ). Given that $Z$ - value is 1.96 for $95 \%$ confidence level, a random sample of size of 384.16 in our target population should be enough to give us the confidence levels needed. The sample size is the adjusted to the estimated mobile phone subscribers ( $N=36.75$ million) using the Cochran equation for adjusted population size:

$$
\mathrm{n}=\mathrm{n}_{0} /\left(1+\left(\left(\mathrm{n}_{0}-1\right)\right) / \mathrm{N}\right) .
$$

So for mobile phone users estimated population, 384 respondents are needed for this study. According to sample distribution table, the sample size is 384 provided the target population is more than 100,000 (Krejce and Morgan, 1970). 
The questionnaires were administered via two conduits. First, authors employ a simple random sampling approach to hand deliver the questionnaires. Research assistants distributed questionnaires to households from door to door. A total of 217 valid responses were collected. Collecting questionnaires on the spot improves reliability and raises the response rate of the descriptive assessment (Wang et al. 2011). Second, to make the study more representative, authors uploaded and shared the questionnaire web URL to respondents. Respondents' anonymity was guaranteed to encourage substantial feedback. A total of 198 valid responses were collected. Collecting data online is expedient in that it is a platform for a broad and geographically distributed population, budget efficient, time convenient, and tackles the problem of interview biasness.

As the questionnaires were administered through two conduits, authors guaranteed that double entries were averted. Respondents from the door-to-door survey did not engage in the web survey. In total, 415 valid responses from 490 respondents, making it a total response rate of $84.7 \%$. To determine the disparities between responses for key items in the two survey conduits (Purcell and Magette, 2010), an independent sample t-test was implemented. The findings obtained from t-test for equality of means and Levene's test for equality of variances did not present any statistically significant difference. Therefore, the sample data acquired via the two survey conduits were merged for data analysis using SPSS and EVIEWS softwares.

In line with similar studies like Duarte Alonso et al. (2013), independent t tests and the Games-Howell posthoc test were utilized to examine whether substantial differences within age and gender groups existed regarding the Likert-type attributes being measured. Authors chose the Games-Howell post-hoc test because it does not assume a normal distribution of the values (homogeneity of variances) or equal sample sizes.

The reliability of the measurement items was established with Cronbach's alpha to evaluate the internal consistency of the constructs in Table 7. Cronbach's alpha was utilized to assess whether the data relating to the mobile network service factors being tested (refer to Table 7) were internally reliable. The results obtained i.e. 0.892 exceeds the 0.60 threshold as proposed by Hair et al., (1998).

\section{Results and Discussion}

This section provides data analysis, results, and interpretation of the findings. Data analysis was performed using EVIEWS and SPSS softwares and the results of the analysis was established on the aims of this research. During the survey, 490 questionnaires were randomly distributed to mobile network users. Unfortunately, 75 questionnaires were not responded appropriately, so the analysis was made based on 415 responded questionnaires. Table 1 to Table 4, Figure 2 to Figure 7 show the principal demographic characteristics such as gender, age, family size, marital status, educational qualification, among others of the respondents included in the research sample.

Table 1. Gender

\begin{tabular}{|l|l|l|}
\hline & Frequency & Percent \\
\hline Male & 233 & 56.1 \\
\hline Female & 182 & 43.9 \\
\hline Total & 415 & 100 \\
\hline
\end{tabular}

From the findings majority of the subscribers were males comprising $233(56 \%)$ of the respondents while 182 $(44 \%)$ were females.

Table 2. Age

\begin{tabular}{|l|l|l|}
\hline Age & Frequency & Percent \\
\hline $18-29$ & 197 & 47.5 \\
\hline $30-49$ & 148 & 35.6 \\
\hline $50-64$ & 65 & 15.7 \\
\hline $65+$ years & 5 & 1.2 \\
\hline Total & 415 & 100 \\
\hline
\end{tabular}

Findings indicated that majority of the respondent's age were between 18-29 years comprising $39 \%$ while $34.9 \%$ were aged $30-39$ years. On the other hand, $13.7 \%$ were aged between $40-49$ years with $7.5 \%$ aged 19 years and below. Most of the subscribers fell between 20-39 years age range.

Table 3. Marital Status

\begin{tabular}{|l|l|l|}
\hline Marital status & Frequency & Percent \\
\hline Single & 269 & 64.8 \\
\hline Married & 142 & 34.2 \\
\hline Divorced & 4 & 1.0 \\
\hline Total & 415 & 100 \\
\hline
\end{tabular}

From all indications most of the respondents were single comprising 54.5\%, $44.6 \%$ were married and $1 \%$ were divorced. 


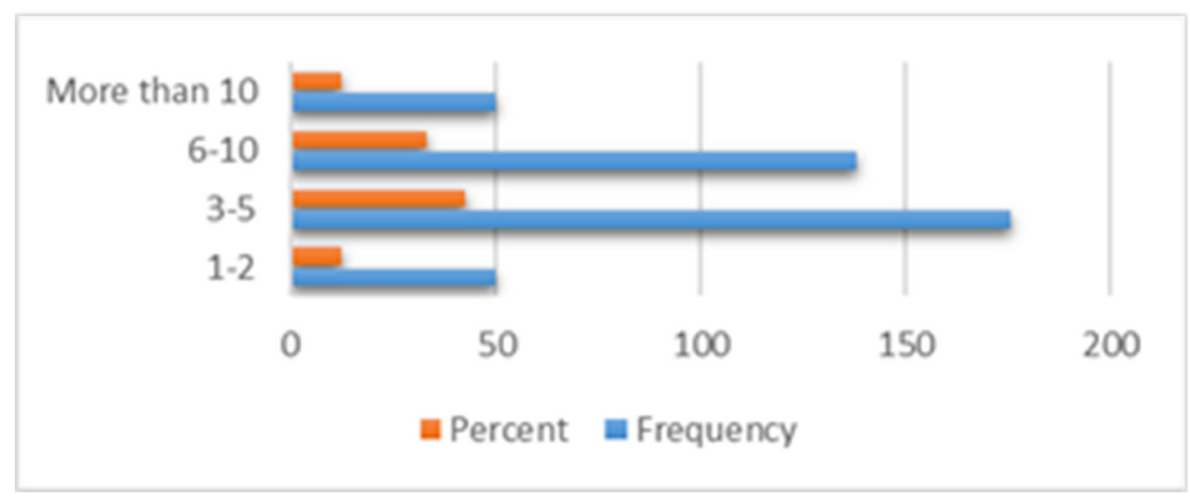

Figure 2. Number of family members

From Figure 2 majority of the respondent's family members were between 3-5 comprising $42.4 \%$ followed by $6-10$ with $33.3 \%$. More than 10 and between 1-2 members had the same frequency of 50 respondents.

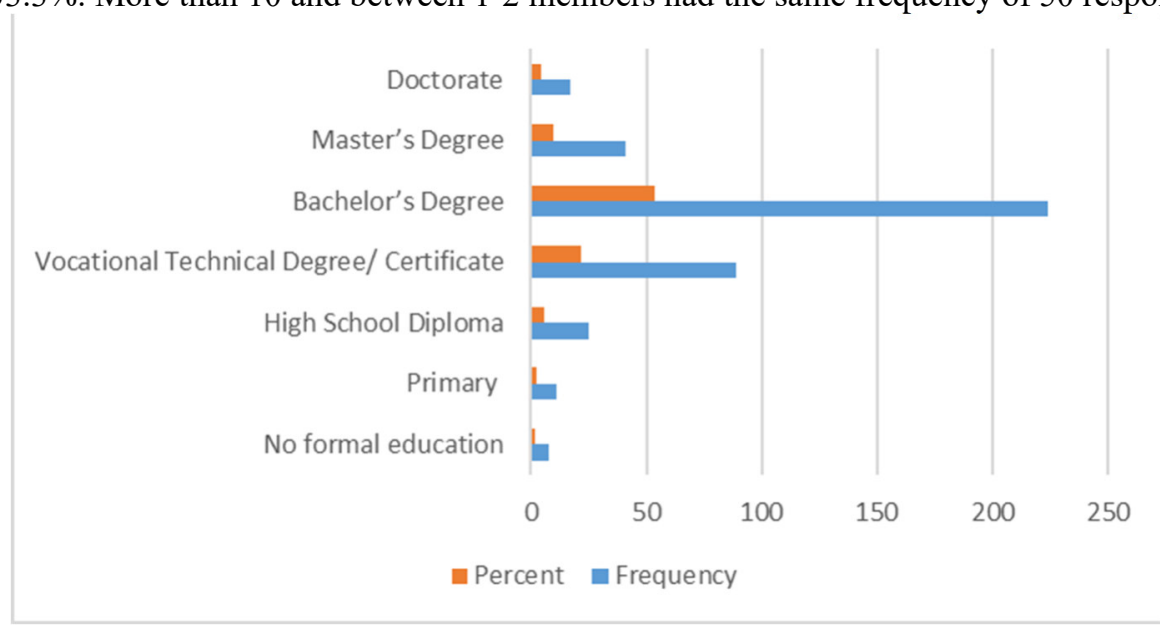

Figure 3. Educational level

$54 \%$ of the respondents had attained their Bachelor's Degree followed by $21.4 \%$ with Vocational Technical Degree while Masters had $9.9 \%$ of the respondents. The study also shows that Doctorate and High school Diploma had $4.1 \%$ and $6 \%$ respectively, while primary and no formal education had 2.75 and $1.9 \%$ respectively. Most of the respondents were educated and young as seen earlier, this is crucial since educational level allows subscribers to search through options available and select best one, which will satisfy their need or want.

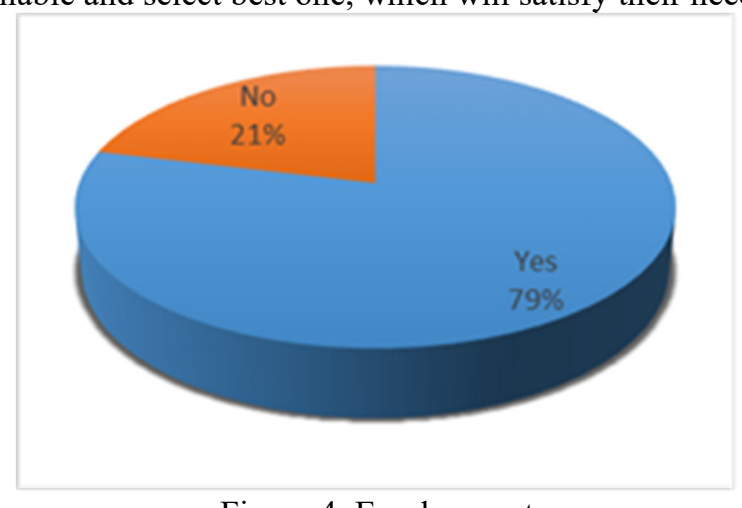

Figure 4. Employment

The findings shows that most of the respondents $79 \%$ were in employment while $21 \%$ were not in any form of employment. Employment status (either employed or unemployed) affects a subscribers choice of mobile network service provider since it affects the income level (purchasing power) of the subscriber. 
Table 4. Occupation

\begin{tabular}{|l|l|l|}
\hline Occupation & Type of Employment & Percent \\
\hline Type of engagement & Self-employed & 29.3 \\
\hline & Employed by an organization & 52.6 \\
\hline Type of skill & Unemployed & 18.1 \\
\hline & Skilled worker & 93.9 \\
\hline Employing organization & Unskilled worker & 6.1 \\
\hline & Non-profit organization & 5.0 \\
\hline & Private organization & 64.6 \\
\hline & Public organization & 29.4 \\
\hline
\end{tabular}

Findings show that $52.6 \%$ of the respondents were employed by an organization while $29.3 \%$ were selfemployed. $18.1 \%$ were however unemployed. When further enquired about their skills $93.9 \%$ of the respondents were skilled workers while $6.1 \%$ were unskilled workers. The private sector encompasses $64.6 \%$ of the employed respondents, which is the majority share while public sector employed $29.4 \%$ of the employed respondents; nonprofit organizations employed $5 \%$ of the employed respondents. This shows that most of the respondents were in an occupation generating income.

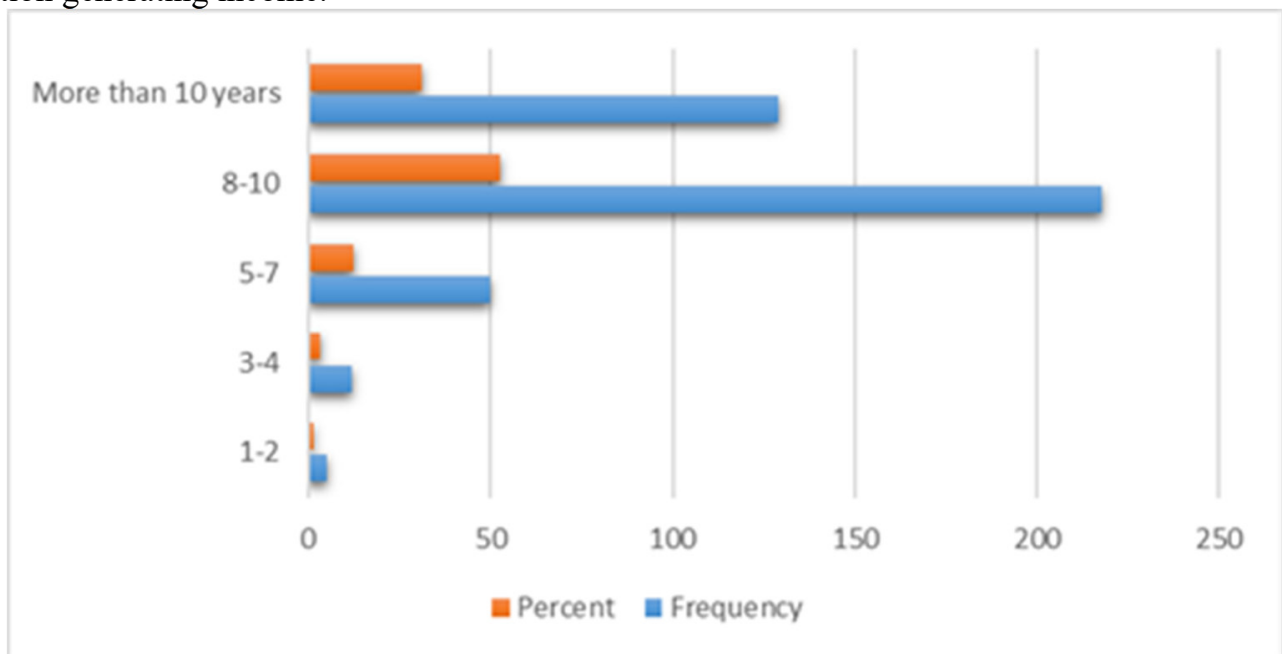

Figure 5. Number of years on network

Most of those who responded had been on their mobile network within 8-10 years range (52.5\%) while $31.2 \%$ had been on it for more than 10 years. $12.1 \%$ of the respondents within $5-7$ years range, 3\% within 3-4 years range and $1.2 \%$ had used for $1-2$ years. The study therefore shows that majority of subscribers had been on their mobile network for more than eight (8) years.

\begin{tabular}{|c|c|c|c|c|}
\hline \multirow[t]{2}{*}{ Mobile network use } & \multicolumn{2}{|l|}{ Yes } & \multicolumn{2}{|l|}{ No } \\
\hline & Frequency & Percent & Frequency & Percent \\
\hline MTN & 303 & 73 & 112 & 27 \\
\hline Vodafone Ghana & 166 & 40 & 249 & 60 \\
\hline AirtelTigo & 95 & 23 & 320 & 77 \\
\hline Glo Ghana & 12 & 3 & 403 & 97 \\
\hline
\end{tabular}




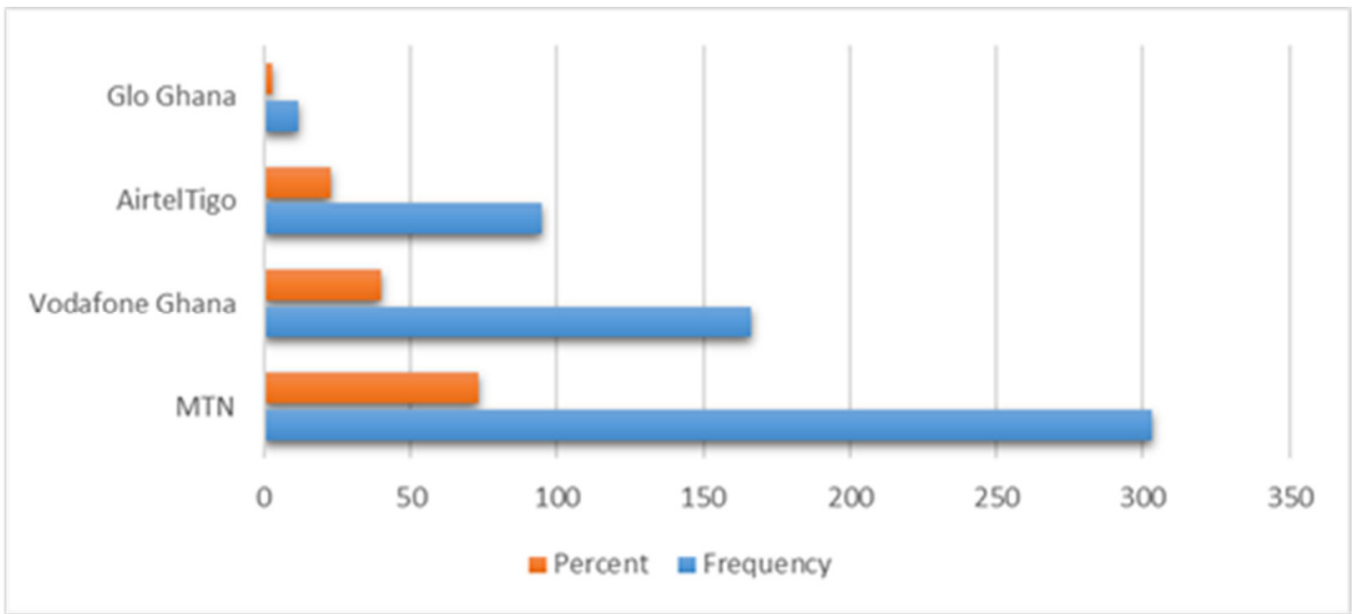

Figure 6. Most used network

From the table and figure above, findings show that most of the respondents used MTN comprising $73 \%$ while $40 \%$ used Vodafone Ghana. AirtelTigo had 23\% and 3\% used GLO. When respondents were asked further "why they used more than a single mobile network service provider and which line they used most of the time". They gave reasons such as cheaper rates, lower data charges, speed in connectivity, reduced congestion, easier money transfer services, to reach friends and family, enjoy benefits from both networks and due to internet access services. MTN dominated the market share whiles Vodafone Ghana followed and AirtelTigo came third.

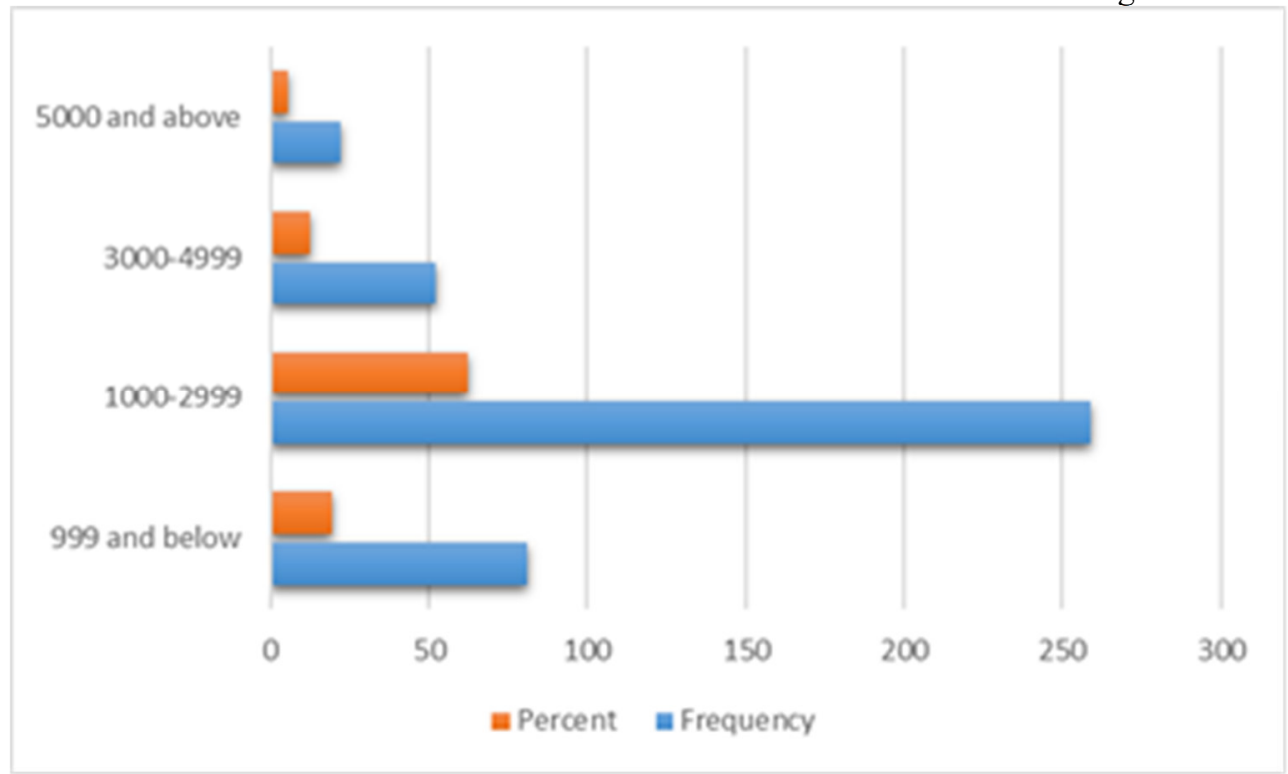

Figure 7. Monthly income of subscribers

The results shows that most respondents earned between GHC 1,000 and GHC 2,999 comprising $62.4 \%, 19.6 \%$ earned GHC 999 and below. On the other hand, 12.6\% earned between GHC 3000 to 4999 while $5.4 \%$ earned GHC 5000 and above per month. According to Ahmed et al. (2016) a subscribers income level helps in making a decision about spending, this income - purchasing power determines whether a subscriber will purchase a product / service or not. Subscribers who earn more income engage in more spend as their level consumption and need for luxuries increases when income level improves.

One of the research questions that was embodied in the questionnaire was devised for subscribers to specify with their own choice of words which particular or one factor drives their choice to subscribe to one mobile network provider over the other. This was done to extract subscribers' feedback and act as a benchmark in formulating scaled constructs. 
Table 6. Factors respondents indicated, with their own choice words, in reaction to the query, "What one factor more than any other drives your decision to subscribe to one mobile service provider over another?"

\begin{tabular}{|l|l|l|}
\hline Item & $\mathrm{n}$ & Percentage \\
\hline My family and friends are already on the network & 121 & 29.16 \\
\hline It was a gift so I had no choice & 7 & 1.69 \\
\hline $\begin{array}{l}\text { Majority of my colleagues or business associates are already on } \\
\text { the network }\end{array}$ & 78 & 18.80 \\
\hline Majority of subscribers in the country are on the network & 43 & 10.36 \\
\hline The mobile network has low voice and data rate & 110 & 26.51 \\
\hline The mobile network has strong connection in my location & 25 & 6.02 \\
\hline The mobile network has good reputation & 9 & 2.17 \\
\hline Provides easy access to services and merchandise & 18 & 4.34 \\
\hline
\end{tabular}

Note: The percentages were calculated based on 415 respondents, out of which 4 referred to other factors that had no more than one response each.

From Table 6 the item, my family and friends are already on the network dominated with (29\%), followed by the mobile network has low voice and data rate $(26.51 \%)$ and majority of their colleagues or business associates were already on the network (18.80\%). According to Rani (2014), social factors such as social networks, family, and societal environment influences consumer behavior. Nevertheless, fewer respondents subscribed to their mobile network because it was a gift and that they did not have much choice as shown by a percentage of 1.69.

One of the research questions which was represented in the questionnaire was designed for subscribers to select how important they considered the listed factors that drives their decision to subscribe to one mobile network provider over another. The listed factors were obtained after extensive literature review, respondents' feedback, and expert's opinion on the subject matter. A 5-point Likert scale: $1=$ Very Important, $2=$ Important, $3=$ Moderately Important, 4= Slightly Important, 5= Unimportant, was used.

Table 7. Mean values of the items subscribers measured in response to the query, "To what degree are the ensuing factors important in your choice of one mobile service network provider over the other?"

\begin{tabular}{|l|l|l|}
\hline Item & Mean & Standard deviation \\
\hline Economic-related factors & 1.94 & 0.9334 \\
\hline Sim card price & 1.39 & 0.5556 \\
\hline Low voice and internet data rate & 1.42 & 0.5019 \\
\hline Moderate cost of services and promotional packages & 1.58 & 0.5019 \\
\hline Efficiency-related factors & 2.36 & 0.7833 \\
\hline Consistent and dependable mobile network & 2.09 & 0.8197 \\
\hline Available, courteous, friendly and helpful customer care & 1.33 & 0.5951 \\
\hline Provides easy access to services and merchandise & 2.21 & 0.6963 \\
\hline Social-related factors & 3.61 & 0.8993 \\
\hline Closed User Group (CUG) services for Family and friends & \multicolumn{2}{|l|}{} \\
\hline CUG services for Business and Associates & 1.55 & 0.6170 \\
\hline Company's brand / participation in charity & 1.36 & 0.6030 \\
\hline Technical-related factors & 2.85 & 0.8337 \\
\hline Clear and uncongested network & 1.45 & 0.5056 \\
\hline Strong network signal strength - fast data connectivity & $2.85)$ & \\
\hline Good contract features & " Available, \\
\hline Nationwide coverage &
\end{tabular}

Table 7 shows that the feature "Good contract features" (Mean = 2.85) and item "Available, courteous, friendly and helpful customer care" (Mean=2.36) are evidently marginal when choosing one mobile network provider over the other.

The finding underpins the view that respondents consider this aspect as very important component in their mobile network service experience. Certainly, when the Likert-scale type items used in this research were answered by the respondents, in eight instances the average scores was at or below the importance level (or Mean $=2$ and below). Closed User Group (CUG) services for Family and friends was the item that is very important to subscribers $($ Mean $=1.33)$.

The response shows that most subscribers considered most highly different items when deciding on their mobile network service provider. The items include closed user group services for family and friends, network signal strength, low voice and internet rate, moderate cost of services, nationwide coverage, clear and uncongested network, consistent and dependable mobile network as indicated by low average values of 1.33, 1.36, 1.39, 1.42, $1.45,1.55$, and 1.58 correspondingly. The least considered items were company's brand and good contract features, as indicated by high average values of 3.61 and 2.85 respectively. 
While level of income is not a factor in determining subscriber choice, numerous dissimilarities were observed amid other groups of respondents specifically gender and age and the constructs under measurement (refer to Table 8). The level of importance females assigned to CUG services for family and friends, as well as concerning the company's brand / participation in charity items was clearly considerably important compared to males.

Table 8. Independent $t$ and Games-Howell post-hoc tests for groups and choice of mobile network service provider

\begin{tabular}{|c|c|c|c|c|}
\hline Items & Variables & Mean & $\begin{array}{l}\text { Standard } \\
\text { deviation }\end{array}$ & Sig. \\
\hline $\begin{array}{l}\text { Gender vs. Factors influencing subscribers' choice of } \\
\text { mobile network service provider }\end{array}$ & \multicolumn{4}{|l|}{ Gender } \\
\hline \multirow[t]{2}{*}{ Company's brand / participation in charity } & Males & 3.94 & 0.8553 & 0.012 \\
\hline & Females & 3.52 & 0.8102 & \\
\hline \multicolumn{5}{|l|}{ Closed User Groups (CUG) services } \\
\hline \multirow[t]{2}{*}{ Business and Associates } & Male & 2.19 & 0.6582 & 0.009 \\
\hline & Females & 2.32 & 0.6509 & \\
\hline \multirow[t]{2}{*}{ Family and friends } & Male & 1.52 & 0.5075 & 0.002 \\
\hline & Female & 1.27 & 0.4352 & \\
\hline $\begin{array}{l}\text { Age vs. Factors influencing subscribers' choice of } \\
\text { mobile network service provider }\end{array}$ & \multicolumn{4}{|l|}{ Age } \\
\hline \multirow[t]{4}{*}{ Company's brand / participation in charity } & 1. $18-29$ & 3.77 & 0.8245 & \\
\hline & $2.30-49$ & 3.46 & 0.8102 & $<0.01(2,1)$ \\
\hline & $3.50-64$ & 3.89 & 0.8856 & $<0.01(3,2)$ \\
\hline & 4. $65+$ & 3.92 & 0.8954 & $<0.01(4,3)$ \\
\hline \multirow[t]{4}{*}{ Available, courteous, friendly and helpful customer care } & $1.18-29$ & 2.21 & 0.5246 & \\
\hline & $2.30-49$ & 2.26 & 0.5627 & $<0.01(2,1)$ \\
\hline & $3.50-64$ & 2.34 & 0.6794 & $<0.01(3,2)$ \\
\hline & 4. $65+$ & 2.39 & 0.6141 & $<0.01(4,3)$ \\
\hline \multirow[t]{4}{*}{ Low voice and internet data rate } & 1. 18-29 & 1.22 & 0.4158 & \\
\hline & $2.30-49$ & 1.24 & 0.4896 & $<0.01(2,1)$ \\
\hline & $3.50-64$ & 1.36 & 0.5178 & $<0.01(3,2)$ \\
\hline & 4. $65+$ & 1.42 & 0.5968 & $<0.01(4,3)$ \\
\hline
\end{tabular}

From Table 8. Female respondents with the mean score of 3.52 considered company branding at a higher level in their choice for the mobile network service provider as compared to 3.94 of male respondents at a $5 \%$ significance level. This coincides with a study by Lakshmi et al., (2017) who revealed that males and females are completely different at every stage of purchase decisions. Females prefer strong colors and evocative experiences, which brings strong memories or feelings to mind. Females consider company's branding and participation to charity more than the males. Both genders portray dissimilar behaviors in relation to purchasing mobile network services.

According to Bakshi (2012), women tend to be internally focused people as they talk to connect with others and place more value in emotional connections and relations whiles men are more externally focused as seen in the mean score of 1.27 of female respondents for CUG services for family and friends at a statistically significant difference $(p<0.01)$. A statistically significant difference $(p<0.01)$ was obtained when comparing the level of importance to group of respondents with respect to CUG services for Business and Associates. The 2.19 mean score for male respondents for CUG services for Business and Associates as shown in the table concurs with a research by Wachira (2012), which showed that most male respondent considered business and associates at a higher level of importance in their purchase decisions. It is very imperative that mobile network service providers understand males and females based tendencies to better satisfy the subscribers.

With company's branding and charitable works, subscribers' between the age range of 30-49 years had the lowest average value of 3.46 followed by age range 18-29 years with a mean score of 3.77, 50-64 with 3.89 and 65 years and over with 3.92. Subscribers within the age range of 18-29 considers very highly available, courteous, friendly and helpful customer care when choosing a mobile network provider as shown by their mean scores of 2.21 followed by 30-49 with 2.26, 50-64 with 2.34 and 65 years and over with 2.39 . All subscribers considered low voice and internet data rate highly as shown by the high mean score in Table.8. The highest age group was 
between the range of 18-29 with a mean score of 1.22 followed by 30-49 with 1.24, then 50-64 with 1.36 and 65 plus with 1.42 .

This research investigated the mobile network services mostly used by the subscribers. The researchers used a Likert scale of $1=$ Always, $2=$ Often, $3=$ Sometimes, $4=$ Rarely, and $5=$ Never.

Table 9. Frequency of usage of various mobile network services

\begin{tabular}{|l|l|l|}
\hline Mobile network service used & Mean & Standard deviation \\
\hline Voice & 1.39 & 0.6586 \\
\hline Internet & 1.18 & 0.4647 \\
\hline SMS & 2.94 & 1.0589 \\
\hline Mobile commerce & 2.15 & 0.8337 \\
\hline Entertainment & 2.21 & 0.9158 \\
\hline
\end{tabular}

Findings of Table 9 indicated that most respondents always made use of internet and voice mobile services as evidenced by 1.18 and 1.39 mean scores respectively. Mobile commerce and Entertainment were often used as shown by mean score of 2.15 and 2.21 respectively. However, services such as SMS were not used as often as shown by a mean score of 2.94. Many factors influence usage of different mobile network services. In concurrence to Rani (2014), the decision of the subscriber is impacted by cultural trends, social class, membership groups, personal characteristics, family, etc. It is imperative to understand the needs and wants of the subscriber to focus on more efficient ways to target and reach them.

Regarding age groups, some differences were observed with respect to their usage of mobile network services. Table 17, demonstrates that majority of respondents who used voice were between the age range of 50-64 followed by $30-49$, then $18-29$ with the least being $65+$ as presented by the mean scores of $1.47,1.51,1.53$ and 1.54 respectively. This is in line with National Communication Authority (NCA) of Ghana statistics on industry voice subscription, which shows a decline of $0.05 \%$ as at June 2019 . This can be attributed to mobile phone apps, which allows subscribers to communicate without the use of mobile voice services.

Table 10. Age and the usage of various mobile network services using Games-Howell post-hoc test

\begin{tabular}{|c|c|c|c|c|}
\hline Items & Variables & Mean & $\begin{array}{l}\text { Standard } \\
\text { deviation }\end{array}$ & Sig. \\
\hline $\begin{array}{l}\text { Age groups vs usage of various mobile network } \\
\text { services }\end{array}$ & \multicolumn{4}{|l|}{ Age } \\
\hline \multicolumn{5}{|l|}{ Voice services } \\
\hline & 1. 18-29 & 1.53 & 0.7977 & \\
\hline & $2.30-49$ & 1.51 & 0.7602 & $<0.01(2,1)$ \\
\hline & $3.50-64$ & 1.47 & 0.6944 & $<0.01(3,2)$ \\
\hline & $4.65+$ & 1.54 & 0.7071 & $<0.01(4,3)$ \\
\hline \multicolumn{5}{|l|}{ Internet services } \\
\hline & 1. 18-29 & 1.13 & 0.3711 & \\
\hline & 2. 30-49 & 1.20 & 0.4992 & $<0.01(2,1)$ \\
\hline & 3. 50-64 & 1.92 & 0.9071 & $<0.01(3,2)$ \\
\hline & $4.65+$ & 3.01 & 1.0986 & $<0.01(4,3)$ \\
\hline \multicolumn{5}{|l|}{ SMS } \\
\hline & $1.18-29$ & 2.95 & 1.2352 & \\
\hline & $2.30-49$ & 2.43 & 0.8944 & $<0.01(2,1)$ \\
\hline & 3. 50-64 & 2.56 & 0.9962 & $<0.01(3,2)$ \\
\hline & $4.65+$ & 3.25 & 1.2122 & $<0.01(4,3)$ \\
\hline \multicolumn{5}{|l|}{ Mobile commerce } \\
\hline & 1. $18-29$ & 1.83 & 0.6887 & \\
\hline & $2.30-49$ & 1.97 & 0.5477 & $<0.01(2,1)$ \\
\hline & $3.50-64$ & 2.06 & 0.7012 & $<0.01(3,2)$ \\
\hline & $4.65+$ & 2.57 & 0.7071 & $<0.01(4,3)$ \\
\hline \multicolumn{5}{|l|}{ Entertainment } \\
\hline & 1. $18-29$ & 2.41 & 1.4126 & \\
\hline & 2. 30-49 & 2.99 & 1.3484 & $<0.01(2,1)$ \\
\hline & 3. $50-64$ & 3.12 & 1.3038 & $<0.01(3,2)$ \\
\hline & $4.65+$ & 3.64 & 1.4263 & $<0.01(4,3)$ \\
\hline
\end{tabular}

From the Table 10, most of the respondents used internet services often as shown by the mean score of 1.18 with most of internet users between the age range of 18-29 years of age, followed by those between 30-39 years 
of age as shown by high mean scores of 1.13 and 1.20 respectively. This study shows that majority of the young people used internet services. In line with Hargittai et al. (2018), this research has shown that most of the respondents were from a more privileged background - educational level (refer to Figure 3) and tend to have higher internet skills, which links to more diverse uses and the potential to benefit from the internet more

From the study, Short Message Service (SMS) was mostly used by subscribers between the age range of 3049 years followed by 50-64 then 18-29 with 65 and over being the least as shown by the mean scores $2.43,2.56$, 2.96 and 3.25 respectively. With access to the internet and most of the mobile messaging apps like WhatsApp, among others. Anderson (2016) concludes WhatsApp is internationally popular and its impact and potential is very massive and will enhance communication and services. Most young subscribers will opt for these because of the increase in smartphones and internet savvy.

Most subscribers used mobile commerce such as M-banking, money transfer, M-marketing as shown by the mean score of 2.15 with majority of the subscribers between the age range of 18-29 years, followed by 30-49 then 50-64 with 65 years and over being the least. According to Statista Research Department on a research of distribution of mobile banking users by age group, it was observed that the share of mobile banking users in the 18-29 age group increased to $67 \%$ in 2015 from $45 \%$ in 2011.

Most of the subscribers between the age range of 18-29 years had the highest mean score of 2.41 followed by 30-39 years with a mean score of 2.99, then 40-64 with a mean score of 2.96 with 65 and over being the least with a mean score of 3.25. According to Kuoppamäki et al. (2017), mobile entertainment is most typical for younger subscribers.

The respondents were additionally queried if they were to change their existing mobile network service provider, what elements they wanted the new mobile network service provider to have. Thus, this study used a Likert scale of 1 = Definitely, $2=$ Probably, 3 = Possibly, $4=$ Probably not, $5=$ Definitely not.

Table 11. Attributes subscribers will desire the new mobile network provider to have

\begin{tabular}{|l|l|l|}
\hline Items & Mean & $\begin{array}{l}\text { Standard } \\
\text { deviation }\end{array}$ \\
\hline Fast connectivity and roll over internet bundles & 1.15 & 0.5075 \\
\hline $\begin{array}{l}\text { Low cost of products and services offered (voice and data bundles, mobile money } \\
\text { charges) }\end{array}$ & 1.48 & 0.8337 \\
\hline Consistent and dependable network & 1.45 & 0.7538 \\
\hline Courteous, friendly and helpful customer care & 1.76 & 0.8671 \\
\hline After sale technical support & 1.61 & 0.8638 \\
\hline Promotions and packages for friends, family, associates. etc. & 1.97 & 0.9515 \\
\hline Company's brand / participation in charity & 2.39 & 1.0589 \\
\hline Clear and uncongested network & 1.55 & 0.8693 \\
\hline Nationwide coverage & 1.42 & 0.6629 \\
\hline No. of subscribers in the network & 2.67 & 0.9895 \\
\hline
\end{tabular}

Findings showed that majority of the respondents revealed if they were to switch from their current mobile network, they would go for a network provider that has the following features: fast internet connectivity and roll over of data, nationwide coverage, consistent and dependable network, low cost of products and services offered, clear and uncongested as very important factors when choosing a mobile service provider as was shown by mean scores of $1.15,1.42,1.45,1.48$, and 1.55 respectively. Nonetheless, this research observed that the mobile network service consumers considered characteristics such as company's brand and number of subscribers in the network as unimportant as indicated by mean values of 2.39 and 2.67 respectively.

\section{Conclusion}

The significance of the mobile telecommunication industry to Ghana in terms of economic growth and employment is indisputable. However, mobile service providers face a lot of challenges in their chase for success and survival in their competition, labor force, government policies, and uncertain financial setting. To be equipped to face these problems, mobile network service providers must identify all the trends and development happening in the industry, especially about subscribers. In previous and recent times, more studies have been undertaken to increase knowledge about mobile network service subscribers, their demands and wishes.

This research sought to add to the literature on mobile subscribers' perceptions of attributes that are essential in their choice of mobile service providers. This study needed to allow subscribers to qualitatively express in their own words the factors most important during selection. Furthermore, this research presented items identified in previous telecommunication studies and added other relevant factors (e.g. strong network signal strength) that are less tested in recent studies. The mean score regarding good contract features (2.85) and available and helpful customer care (2.36) are marginal when choosing one mobile network provider over another.

From the statistical findings, subscribers written responses show the prominence of family and friends being 
on the same mobile network, and low voice and data rate as essential factors when selecting a mobile service provider. The mean values of measured items implied that closed user group services for family and friends, network signal strength, low voice and internet rate, moderate cost of services, nationwide coverage, clear and uncongested network and, consistent and dependable mobile network are considered in the list of most valued items.

The results also accentuated some dissimilarities among groups (age and gender) and factors affecting the choice of the mobile network service provider. Females placed high importance on the CUG services for family and friends and the company's brand/participation in charity items. Respondents within the age range of 18-29 years consider very highly low voice and internet data rate as well as available, courteous, friendly and helpful customer care. With groups and prominence placed on selected attributes linked to mobile network services, respondents within the age range of 18-29 years had the highest mean score for internet, voice, entertainment and e-commerce services. The age range of 30-49 years had the highest mean score for SMS.

The mean score regarding what subscribers will look out for in their new service provider in case of switching showed that most of the subscribers' were less content with their current experiences. Most importantly, subscribers will consider the following attributes very highly when switching to a new mobile network service provider. The attributes are fast internet connectivity and rollover of data, nationwide coverage, consistent and dependable network, low cost of services and products offered, and clear and uncongested network.

Demographic characteristics (specifically, age and gender) of the subscribers influence the choice of mobile service network provider in Ghana. While females were influenced by family and friends, and the company's brand/charitable works, the males were affected by items such as work and business groups. Age also came out as a determining factor when choosing a mobile network service provider. Findings show that young subscribers (1829 years) were more influenced by services such as internet, voice, entertainment and mobile commerce. From the study, most of the respondents selected social-related factors such as business or work groups, friends and family members as an important factor. Findings show that most respondents had subscribed to their respective mobile services providers because their family and friends were on the network. Concerning economic-related factors, most subscribers considered mobile network service providers with a low voice and internet data rate in their decision-making process. Effectiveness and efficiency are at the core of what subscribers patronize, and thus a baseline benchmark of the effect of brand integrity. The service provider must understand how customers perceive their service efficiency in provision to consistent and dependable network services. About technical-related factors, most subscribers considered mobile network service providers with strong network signal strength in their decision-making process.

Authors recommend mobile network providers formulate policies and tactics to attain viable economic advantage - designing products or services that are exclusive to a specific section of consumers to entice new mobile network subscribers at a low cost. It is valuable for mobile network service providers to pursue network effect phenomena since most subscribers choose their network because family and friends were already on it. To provide efficient services, it is prudent for mobile network providers to invest significantly in technological innovations that would improve nationwide coverage, provide clear and uncongested network, and offer faster data services and low service rates or charges.

The authors recognize the absence of a longitudinal method in this research. In addition, this study focused more on the urban areas where mobile saturation rate is high in comparison to that of the national saturation rate. Instead, the findings of this present study only provide primary insights into the mobile network subscribers' choice to gain more perspective of the various competing and influencing factors that drive subscribers' choice of mobile service provider and patronage in Ghana. Authors suggest longitudinal study and a focus on rural areas for future research. It is also feasible to use the findings from other approaches to compare the results of this study under the scope of gaining additional insight with the motivation of adding significant value to subscribers' choice and mobile telecommunication industry.

\section{Acknowledgement}

The authors would like to thank Ebenezer F.E. Atta Mills, $\mathrm{PhD}$ for his valuable inputs and suggestions. The authors acknowledge support from School of Management, Jiangsu University, Zhenjiang, China.

\section{References}

Agyapong, G. K. (2011). The effect of service quality on customer satisfaction in the utility industry-A case of Vodafone (Ghana). International Journal of Business and management, 6(5), 203-210.

Ahmed, M. E., Khan, M. M., \& Samad, N. (2016). Income, Social Class and Consumer Behaviour: A Focus on Developing Nations. Journal of Applied Business and Economic Research, 14(10), 6679-6702.

Alam, M. A., Roy, D., \& Akther, R. (2016). Consumers' Expectation and Perception toward Mobile Telecommunication Usage in Bangladesh. Asian Business Review, 6(1), 8-64.

Ali, R., Leifu, G., YasirRafiq, M., \& Hassan, M. (2015). Role of perceived value, customer expectation, corporate 
image and perceived service quality on the customer satisfaction. Journal of Applied Business Research $(J A B R), 31(4), 1425-1436$.

Alshurideh, M., Al Kurdi, B. H., Vij, A., Obiedat, Z., \& Naser, A. (2016). Marketing ethics and relationship marketing-An empirical study that measure the effect of ethics practices application on maintaining relationships with customers. International Business Research, 9(9), 78-90.

Anderson, K. (2016), "Getting acquainted with social networks and apps: WhatsApp-ening with mobile instant messaging?", Library Hi Tech News, Vol. 33 No. 6, pp. 11-15.

Arndt, J. (1967). Word of mouth advertising and informal communication. Risk taking and information handling in consumer behavior, 188-239.

Bansah, M., Dabi, M., Dzorvakpor, S., \& Nwodo, H. (2015). The Effect of Branding on Consumer Buying Behaviour among Textile Ghana Fabric Users in the Ho Municipality of Ghana. European Journal of Business and Management, 7(26), 117-125.

Bansah, M., Dabi, M., Dzorvakpor, S., \& Nwodo, H. (2015). The Effect of Branding on Consumer Buying Behaviour among Textile Ghana Fabric Users in the Ho Municipality of Ghana. European Journal of Business and Management, 7(26), 117-125.

Bakshi, S. (2012). Impact of gender on consumer purchase behaviour. Journal of Research in Commerce and Management, 1(9), 1-8.

Chan-Olmsted, S., \& Jamison, M. (2001). Rivalry through alliances:: Competitive strategy in the global telecommunications market. European Management Journal, 19(3), 317-331.

Chuah, S. H. W., Marimuthu, M., \& Ramayah, T. (2016). The Contribution of Perceived Firm Marketing Innovation Initiatives to Customer Perceived Value and Loyalty: Does Switching Experience Really Matter?. Asian Academy of Management Journal, 21.

Choi, J., Seol, H., Lee, S., Cho, H., \& Park, Y. (2008). Customer satisfaction factors of mobile commerce in Korea. Internet research, 18(3), 313-335.

Clow, K. E., \& Baack, D. (2004). Integrated Advertising Promotion, and Marketing

Cochran, W. G. (1977). Sampling Techniques. John Wiley \& Sons. New York.

Dichter, E. (1966). How word-of-mouth advertising works. Harvard business review, 44(6), 147-160.

Duarte Alonso, A., O'neill, M., Liu, Y., \& O'shea, M. (2013). Factors driving consumer restaurant choice: An exploratory study from the Southeastern United States. Journal of Hospitality Marketing \& Management, 22(5), 547-567.

Duggan, M. (2015), "Mobile messaging and social media", Pewinternet.org, available at: http://www.pewinternet.org/2015/08/19/mobile-messaging-and-social-media-2015/ (accessed 3 July 2016).

Gautam, V. (2015). Service quality perceptions of customers about mobile telecommunication services: a case of India. Journal of Global Marketing, 28(1), 19-31.

Hair, J. F., Anderson, R. E., Tatham, R. L., \& William, C. (1998). Black (1998), Multivariate data analysis.

Hargittai, E., Piper, A. M., \& Morris, M. R. (2018). From internet access to internet skills: digital inequality amo ng older adults. Universal Access in the Information Society, 1-10.

Hassan, M., Hassan, S., Nawaz, M. S., \& Aksel, I. (2013). Measuring customer satisfaction and loyalty through service fairness, service quality and price fairness perception: an empirical study of Pakistan Mobile telecommunication sector. Science International, 25(4), 971-980.

Ishaq, I. M. (2012). Perceived value, service quality, corporate image and customer loyalty: Empirical assessment from Pakistan. Serbian Journal of Management, 7(1), 25-36.

Kim, E. E. K., Mattila, A. S., \& Baloglu, S. (2011). Effects of gender and expertise on consumers' motivation to read online hotel reviews. Cornell Hospitality Quarterly, 52(4), 399-406.

Klein, A., \& Jakopin, N. (2014). Consumers' willingness-to-pay for mobile telecommunication service bundles. Telematics and Informatics, 31(3), 410-421

Koi-Akrofi, G. Y., Koi-Akrofi, J., \& Welbeck, J. N. (2013). Relationship marketing tactics and customer loyaltya case of the mobile telecommunication industry in Ghana. Asian Journal of Business Management, 5(1), 7792.

Krejcie, R. V., \& Morgan, D. W. (1970). Determining sample size for research activities. Educational and psychological measurement, 30(3), 607-610.

Kuoppamäki, S. M., Taipale, S., \& Wilska, T. A. (2017). The use of mobile technology for online shopping and entertainment among older adults in Finland. Telematics and Informatics, 34(4), 110-117.

Lakshmi, V., Niharika, D., \& Lahari, G. (2017). Impact of gender on consumer purchasing behavior. Journal of Business and Management, 19(8), 33-36.

Lewis, A. C. (2000). High-stakes testing: Trends and issues. Aurora, CO: Mid-continent Research for Education and Learning.

Melody, W. H. (2001). Policy Objectives and Models of Regulation", Telecom Reform Principles, Policies and Regulatory Practices, Chapter 2, Edited by William H. Melody, Den Private Ingeniorfond, Technical 
University of Denmark, Lyngby, 387-405.

Nimako, S. G. (2012). Linking quality, satisfaction and behaviour intentions in Ghana's mobile telecommunication industry. European Journal of Business and Management, 4(7), 1-17.

Nimako, S. G., \& Mensah, A. F. (2012). Motivation for customer complaining and non-complaining behaviour towards mobile telecommunication services. Asian Journal of Business Management, 4(3), 310-320.

Purcell, M., \& Magette, W. L. (2010). Attitudes and behaviour towards waste management in the Dublin, Ireland region. Waste management, 30(10), 1997-2006.

Rani, P. (2014). Factors influencing consumer behaviour. International journal of current research and academic review, 2(9), 52-61.

Segarra-Moliner, J. R., \& Moliner-Tena, M. Á. (2016). Customer equity and CLV in Spanish telecommunication services. Journal of Business Research, 69(10), 4694-4705.

Sun, L. B., \& Qu, H. (2011). Is there any gender effect on the relationship between service quality and word-ofmouth?. Journal of Travel \& Tourism Marketing, 28(2), 210-224.

Wachira, E. W. (2012). Factors influencing consumer choice of mobile telephone service provider: a case of households in Nairobi County (Doctoral dissertation, University of Nairobi, Kenya).

Wang, Z., Zhang, B., Yin, J., \& Zhang, X. (2011). Willingness and behavior towards e-waste recycling for residents in Beijing city, China. Journal of Cleaner Production, 19(9-10), 977-984.

\section{Notes}

Note 1. https://www.statista.com/statistics/740154/worldwide-unique-mobile-subscribers-by-region/

Note 2. https://www.statista.com/statistics/498203/number-of-mobile-cellular-subscriptions-in-ghana/ 